Reflexiones 



\title{
Karla Solano. El cuerpo que tú buscas
}

\author{
Luis Fernando Quirós-Valverde
}

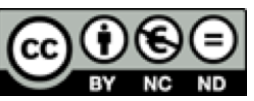

Esta obra está bajo una licencia Creative Commons

Reconocimiento-No comercial-Sin Obra Derivada 



\title{
Karla Solano. El cuerpo que tú buscas
}

\author{
Luis Fernando Quirós-Valverde \\ Universidad Veritas \\ luquiva@gmail.com
}

\section{Resumen}

El ensayo-entrevista sobre Karla Solano, aborda los inicios de su obra en fotografía y el arte contemporáneo y analiza el conocimiento del cuerpo humano como una de las grandes temática del arte y el reconocimiento de su propio cuerpo como principal sujeto de estudio, central en sus distintas temáticas, proyectos y exposiciones.

$\mathrm{Al}$ investigar el contexto de su crecimiento como persona creativa, fue indispensable valorar los procesos culturales, políticos y sociales del entorno urbano donde ella creció, los cuales la formaron como artista; lo anterior, con el objetivo de determinar la naturaleza de esas motivaciones e impacto en sus recurrencias estilísticas y conceptuales. Asimismo, se busca abordar los hilos referenciales que entretejieron sus percepciones al dar tan particular y genuino encaje a sus propuestas y focalizar, también, los procesos de conformación de su lenguaje a partir del cuerpo, con sus profundos discursos sobre la vida y la muerte, lo cual implica a sus propuestas en foto-video-instalaciones y performances.

Esta aproximación a su trabajo creativo marca el rumbo creativo de su búsqueda, permite intuir hacia dónde dirige esas exploraciones y cartografías vivenciales, e invita a reflexionar sobre su valor en el arte del siglo XXI en Costa Rica.

Palabras clave: fotografía contemporánea, performance, instalación, creatividad, vida/muerte, investigación, cuerpo.

\begin{abstract}
This essay-interview about Karla Solano deals with the beginning of her work in photography and the contemporary art. It analyzes her knowledge of the human body as one of the central themes of art, using her own body as the main subject of study, a recurrent theme of her projects and exhibitions. After investigating the context she grew up as a creative individual, it became crucial to analyze the cultural, political, and social processes of the urban environment where she was raised and emerged as an artist. It was also necessary to determine the nature of those motivators and their impact in her style and in
\end{abstract}




\section{Reflexiones}

the concepts she developed. The referential threads that interconnected her perceptions were also observed, since they granted a very particular way to make her proposals fit her scheme. Likewise, the nonverbal language using her own body as a starting point were appreciated. She conveys deep messages about life and death, for which photo-video, installations, and performances have become part of her work.

This close look at her creative art sets the path of her also creative search, allowing us to infer the direction of her explorations and cartographic experiences and inviting us to reflect about her value in Costa Rican the XXI century art.

Key words: contemporary photography, performance, installation, creativity, life/death, investigation, body. 


\section{Introducción}

Reflexionar sobre la obra de la artista costarricense Karla Solano (1971), activado por esta aproximación (ensayo-entrevista -en tanto hoy se vuelven constantes las preguntas y respuestas utilizando las redes sociales-), conduce a conocer el significado del "cuerpo" como entidad conceptual en la fotografía contemporánea. Se trata de un sujeto sensible a la argumentación con el lenguaje y sus modos de expresión, todo para interesar al observador -quien intenta reconocer lo aprendido de un arte que se distancia de la mera representación- e implica, en adelante, el espacio a través del manejo de novedosos recursos y técnicas artísticas, dentro de las cuales destacan el ensamble, la instalación, el video instalación, el performance o el video performance, entre otras.

Esta reflexión, además, sugiere investigar el "cuerpo" como soporte de dicha fotografía. Entonces, cabe preguntarse, quizás, ¿cómo está hecha?, ¿con qué recursos y técnicas se produce?, y dilucidar ¿cuáles son las recurrencias estilísticas o referenciales de la autora? En este sentido, este acercamiento a su trabajo permite conocer su pensamiento, saber distinguir el qué, el cómo, o el cuándo del acto creativo, identificar las ideas y emociones mediadoras en la construcción de estas propuestas; teorizar, incluso, acerca de los razonamientos al invitar al espectador a ingresar al interior de esa entidad simbólica y sentirse parte de sus imaginarios, moverse, tal vez, al interior de esa caparazón concebida como "corpus" fotográfico del arte de estos tiempos.

\section{Buscarse a sí misma}

No conozco otra obra de Karla Solano (1971) -ya sea fotográfica, video, performance, ensamble, instalación- donde no esté presente el cuerpo; el propio, con su piel pecosa, abundantes cabellos rizos, franca sonrisa y mirada inquirente como su pensamiento.

En la construcción liminar del lenguaje para su obra, Karla Solano nos presentó su cuerpo fragmentado, de-construido: "Yo soy Tú"(1995), fotomontaje de un metro sesenta de alto por ochenta de ancho, el cual pertenece a la colección del Museo de Arte y Diseño Contemporáneo (MADC). La crítica de arte Dermis Pérez, en el primer catálogo de la colección de ese museo comentó: "Es la reconstrucción fragmentada de un esqueleto en el cual el cráneo tiene como soporte un espejo en el que nos reflejamos" (Pérez-León, 1996).

Con una imagen así -aspecto que retomará en su trabajo de madurez, luego de la experimentación con varios materiales y recursos técnicos-, ella invita al espectador a ser componente activo de la pieza, a meternos en ella y merodear las reminiscencias de su corporeidad fragmentada en cada una de esas radiografías. Toca al visitante del museo -a nosotros sus espectadores- mentalizar esos códigos visuales para reconstruir el concepto del cuerpo, el cual no existe en la realidad física, pero sí en la metáfora, sumiso a un lenguaje y poética propia que desde sus inicios ella viene conformando, buscando, reinventando para marcar su posición en el universo creativo del arte. El eje principal 


\section{Reflexiones}

de la instalación fotográfica es la vertical como el árbol y la naturaleza que comienza a tratar en los performances más recientes-, y una horizontal, insinuada por las manos, o por los huesos de las manos, para direccionar la mirada que anda al garete, buscando descifrar el significado de la pieza.

De la segunda obra en el referido libro Espíritu de una Colección, titulada "Andar la vida" (1995), de cincuenta centímetros de alto, por ciento cincuenta de ancho y diez de fondo, Dermis comenta: "Es una metáfora construida a partir del juego recíproco de la imagen y la forma, un diálogo entre el objeto y su sombra" (Pérez-León, 1996).

El o los objetos -que acompañan las fotos de las radiografías de sus huesos y que se colocan, en este caso, en la horizontal, para sugerir la idea de soporte o pavimento sobre el cual se ejerce la acción de andar la vida-, y a lo cual se refiere la crítica Pérez León, son hormas de madera utilizadas en la fabricación artesanal de calzado, con radiografías de sus pies re-fotografiados para gestionar la imagen de un cuerpo (des)fragmentado, y deconstruido a partir de la relación existente entre las partes de los pies y dichas hormas; se dice, entonces, que, en tanto objeto, el calzado nos hace, deja huella en nosotros. Tal interaccionismo simbólico reaparecerá en adelante en el trabajo de esta artista, para articular lo que ofrece de sí misma y lo que, de forma lógica, vendrá de retorno, pues nuestras acciones en el andar de la vida cotidiana son influenciadas por el efecto boomerang, que tras ser lanzado siempre nos viene de vuelta.
No obstante, aún hay algo más que decir de este fenómeno o de sus piezas y, en especial de "Yo soy Tú": se trata de ese gesto de invitar a entrar en su interioridad a través del espejo, discurso que vendrá en futuras instalaciones donde ella dejará una abertura dimensional, para que los espectadores, de manera simbólica, ingresemos a su vientre, y desde esa posición tan íntima advertir la sensibilidad quizás materna-, que a ella caracteriza.

Vendrá de nuevo esa misma búsqueda pero con otros matices, otros materiales, otras situaciones y circunstancias espacio-temporales: búsqueda-encuentro de sí misma, entre el manto de la hojarasca que caerá del árbol de la vida - de la gran "Ceiba pentadra" sagrada para nuestras culturas aborígenes-, cuando sus hojas se desprenden sigilosas para no tocarla, se moverán cuidadosas para no herirla, y quizás suturar tantas heridas del tiempo bajo las aguas purificadoras del estanque donde ella se protege como si fuera el vientre materno, inmersa en esa cálida luz que rocía sus cabellos y redibuja la transparencia de su rostro.

\section{Superposición corpórea}

Para la muestra del MADC curada por Virginia Pérez-Ratton y Rolando Castellón, $M E$ SóTica II / Centroamérica re-generación, itinerante por importantes ciudades europeas: Madrid, París, Roma, Turín, Apeldoorn Holanda, preparó la instalación "Espejo Interior"(1996); una superposición de varias fotografías sobre película de acetato pegada sobre acrílico traslúcido: una del sistema 
fisiológico muscular, otra con la imagen de su persona en totalidad desnuda y, la tercera, correspondiente al sistema óseo, dispuestas en línea de profundidad -como se leen los microchips en la tecnología actual-, alineando simbólicamente, una vez más, la desfragmentación de su cuerpo, generando una intensa correspondencia biounívoca, cualidad isomorfa cuando los componentes sistemáticos se requieren uno del otro, y en carencia de alguno, el sistema total colapsaría. Tremenda visión la de Karla Solano con esta pieza plena de madurez.

Una vez más Dermis Pérez comenta de sobre la misma:

\begin{abstract}
Al descarnar-se muestra la verdadera urdimbre de la que estamos compuestos bajo la piel: músculos, órganos, huesos, sangre y fluidos corporales. Es un acto de honestidad, busca establecer un diálogo íntimo con el público más allá de lo aparente. Ella nos propone una reconstrucción de la espiritualidad a partir de la arqueología del cuerpo refuncionalizando lo vital-biológico. Su discurso se apoya en lo nítido y transparente, con la finalidad de buscar una identificación con el espectador que se coloca entre los acrílicos al igual que en un penetrable; metáfora de las diferentes capas que nos envuelven y protegen. (Pérez-León, 1997).
\end{abstract}

De esta pieza “Espejo Interior" observé una variante de 2010, expuesta en el guión permanente de la colección del Museo de Arte Costarricense (MAC); a esta instalación la artista agregó dos capas más, generando un juego de superposiciones entre músculos, huesos, piel, e invitó a entrar a su cuerpo al caminar y/o movernos entre las distintas estratificaciones de su cuerpo, a manera de objeto-penetrable, para despejar la incógnita del espejo, del cuerpo que se ve. Así, dicha estructura permite "sentir" a través de la fotografía; se advierte y recompone para vivenciar, de forma simbólica, al sujeto: a sí misma, su cuerpo, su ausencia o presencia, su trascendencia en la obra de arte, que solo logramos percibir a través de esa magia de lo reflejante o carácter espejado del material o soporte.

Sin embargo, ¿por qué agregó esas nuevas capas? La autora comenta que ya habían pasado quince años de la concepción y producción de dicha pieza, y las nuevas capas corresponden a la actualidad de su cuerpo, pues, quizás, cuando se cumplan otros quince años más, es posible que se agreguen nuevas capas.

\section{Relaciones y referencialidades}

En el pasado siglo -década de 1970 y 1980-, hablar de referentes era un término confuso e implicaba influencias difíciles de superar en el trabajo de todo artista, en tanto existe un enamoramiento con la obra de otro. Todos sabemos de qué se trata cuando se advierte la influencia de un Pablo Picasso en gran parte del arte moderno; la pincelada y estilo compositivo de Francis Bacon en la pintura de la Nueva Figuración y, en particular, en la región, e incluso del arte de un 


\section{Reflexiones}

Josef Beuois en el Arte Conceptual y el universo de lo contemporáneo. En la actualidad, aquellas arcaicas preconcepciones que fustigaban la originalidad versus las apropiaciones o las referencialidades fueron totalmente superadas; nada impide al artista recurrir al lenguaje de otros a partir de lo cual considerar o, sobre todo, acrecentar el logro de lo propio, y el trazo del curso de su búsqueda que siempre será intensa.

Aunque en Costa Rica se hablaba de la modernidad introducida tanto por Juan Luis Rodríguez, Otto Apuy y Rafael Ottón Solís -quienes vivieron una importante parte de sus vidas en Europa, e incluso, se les considera como aquellos que introdujeron el Arte Conceptual en el país - como por la Primera Bienal Centroamericana del CSUCA (Consejo Superior Universitario Centroamericano) que confrontó al arte local, el arte contemporáneo tuvo su mejor desarrollo con la creación del MADC en 1994, contando con la acertada dirección de la fallecida Virgina Pérez-Ratton, y el curador Rolando Castellón, quien traía un importante bagaje de su gestión en museos y galerías de California durante la década de los setentas y ochentas.

Una de las muestras que aportó un punto de quiebre en la calidad e intensidad de los estímulos para la creación visual de los artistas locales fue la muestra "RELACIONES" (MADC, 1996), curada por Pérez-Ratton, la cual brindó una oportunidad para apreciar la obra del guatemalteco Luis González Palma, quien expuso las fotografías de la camisa de un masculino, mostrando los orificios por donde penetraron las balas en el conflicto bélico de Guatemala. Impresas en acetato traslúcido, pegadas a una lámina de acrílicos, estaban colgadas delante del muro de la Sala I, de manera que la luz, al incidir sobre la fotografía, proyectaba la imagen ampliada en la pared; recurso que implicó innovación al exponer lo dramático del sujeto-objeto en el "corpus" fotográfico.

Otro de los artistas que infundió gran motivación fue el colombiano Oscar Muñoz, quien expuso un conjunto de telas, como imagen de los cortineros de las duchas, con una exquisita técnica en la cual se apreciaba el dibujo de cuerpos varoniles desnudos. Muñoz trabajaba con carboncillo en polvo, sumergía el soporte en una bandeja con agua, y dibujaba, de forma magistral, aplicando el polvo, y al secar el líquido, la imagen dibujada se transfería al soporte. Esta pieza impactó mucho a los jóvenes artistas locales que desde hacía unos años habían ingresado al laboratorio del arte donde se probaba todo lo posible para innovar y activar las manifestaciones de la creatividad.

Asimismo, el artista belga Win Delvoye fue otro personaje que infundió motivación por su pensamiento y las técnicas con que elaboraba sus esculturas e instalaciones. También trabajaba los cueros de piel de cerdo, sobre los cuales pintaba o imprimía una serie de íconos heráldicos de las culturas del norte europeo. Además, conocíamos el sensible trabajo fotográfico del cuerpo 
femenino, (des)fragmentado y recompuesto dentro de un orden convulso, como inmerso en la deriva del gran Caos, por parte del salvadoreño Luis Paredes.

En el texto curatorial Pérez-Ratton escribe:

RELACIONES es la libertad misma con que cada uno asume lo que percibe como identidad, cúmulo de lo propio y de lo ajeno experimentado como propio, y las reacciones establecidas entre unos y otros dentro de un panorama de expresiones opuestas, pero sin embargo que apuntan hacia una misma dirección -la experiencia de sí mismo, en mayor o menor medida inserto en un entorno social, artístico, cósmico, íntimo, político. (Pérez-Ratton, 2009)

Los mencionados estímulos al lenguaje de los artista locales representaron un fogonazo creativo al trabajo de investigación y experimentación con nuevos materiales; de tal forma, se realizaban consciente e inconscientemente en el arte local durante esos años de apertura del MADC, de manera que las referencias no son vistas como imposiciones estilísticas de percepciones externas, sino como activadores a la creatividad y exigencias de los jóvenes artistas en esos liminares del arte contemporáneo en el país, fenómeno dentro del cual Karla Solano se mostró reactiva, intentando trascender superando dichas nociones con un equilibrio atinado, propio de la madurez que el trabajo constante le brindó.

\section{La piel como soporte fotográfico}

El cuerpo de la fotografía y el cuerpo en la fotografía, que se comenta en el anterior párrafo, fue otra muestra del MADC curada por la guatemalteca Rosina Cazali, Dermis Pérez y el autor de este ensayo, muestra en la cual Karla Solano fue expositora con una pieza quizás, según mi actual criterio, no tan relevante -o como es normal- dentro de los altos y/o bajos de su producción; no obstante, dicha participación representó su inserción en esos procesos de investigación sobre materiales y el uso o aplicación de las nuevas tecnologías de la imagen, aspecto que ofreció otras posibilidades de servirse de una piel distinta, aunque siempre piel. Titulada “De la serie El Ciclo de la Vida" (1998).

En el "statement" la autora aprecia:

Una piel, un sentimiento y un recuerdo; unido por puntadas en el hilo de la vida.

Lo orgánico y lo espiritual son en las membranas un solo cuerpo, maltratado por el transcurso del tiempo.

Para mí las pieles que alguna vez fueron seres que tuvieron vida y murieron, son como anécdotas de cada uno de nosotros que enfrentamos cada día la incertidumbre, lo bello y lo terrible, lo aparente y lo real...

Pero el ciclo de la vida continúa y no nos queda más que reflexionar sobre su verdadero sentido, sin olvidar la magia de la existencia. (MADC, 1998) 


\section{Reflexiones}

En este proyecto expositivo, además de Karla Solano, participaron artistas de la cala de Alexander Apostol de Venezuela, Fernando Arias de Colombia, Marie Ange Bordas de Brasil, Adriana Calatayud de México, Daniel Hernández de Guatemala, Luis Paredes de El Salvador, René de Jesús Peña de Cuba, Misael Ruíz de España, Jaime David Tischler de Costa Rica e Irene Torrebiarte de Guatemala.

En el texto de la co-curadora Rosina Cazali explica:

En los últimos años el arte ha optado por acosar el cuerpo más allá de su presentación literal, ha logrado penetrar el espacio corporal en todos sus rincones y todas sus dualidades para establecer un diálogo con éste y con el mundo que le rodea. Desde sus inicios, el cuerpo se inscribió en la fotografía como un espacio en sí mismo. En la indagación y registro de lo corporal este medio se definió como el más exacto para captar la individualidad y registrar la diversidad de las identidades. (MADC, 1998)

Según mi criterio, en esta muestra en particular, Karla demuestra intentos de inventar su lenguaje y alcanzar horizontes técnicos o expresivos. Aquí, la autora plantea una impresión sobre la piel curada de un cerdo, disponiendo los químicos utilizados para revelar las fotografían puntualmente, luego de proyectar la imagen de su propio rostro y el de una de sus hijas, oportuno en tanto se inserta en un circuito de curadurías en las cuales el "corpus" expositivo lo componen artistas del arte fotográfico internacional -ya mencionados-, quienes introdujeron conceptos y maneras de exponer la fotografía, no solo la imagen fotográfica que en principio fue bidimensional, sino introducir el manejo del espacio y la carga conceptual que adelantó en el país estas manifestaciones de los años noventa de ese siglo. Por otro lado, si consideramos la pieza "Espejo Interior” 1996 -con la cual integró MESóTica II / Centroamérica re-generación- dio un salto significativo, y creo que "El Cuerpo EN/DE la fotografía" la catapultó hacia nuevos y rigurosos desafíos.

\section{Contexto de crecimiento}

Karla Solano nació en 1971, año significativo para el desarrollo futuro del arte local, con la realización en San José de la Primera Bienal Centroamericana de Arte, organizada por el CSUCA, en el recién estrenado edificio de la Biblioteca Nacional. Dicho evento representó una confrontación para los artistas locales a la crítica, con la llegada de la argentino-colombiana Marta Traba, quien impulsaba, en esos años, la Nueva Figuración en el arte.

En los años de esa coyuntura del siglo XX, artistas como Rafael Ángel Felo García, quien estudió en Inglaterra, abrazó la corriente de la Abstracción y, a su regreso al país, formó el Grupo Ocho, coincidiendo con Manuel de la Cruz González, quien introdujo la Abstracción Geométrica y el Constructivismo que tanto revuelo experimentó en América del 
Sur. Asimismo, resalta Juan Luis Rodríguez Sibaja, quien había triunfado en la Bienal de París con la pieza "EL Combate", instalación de un cuadrilátero de boxeo con una silla de hielo teñido de negro y rojo escarlata, el cual, lógicamente, derretía dejando un charco, simbolismo que asimilaba la reflexión sobre los conflictos políticos y sociales que conmocionaron la Europa de postguerra, y las luchas estudiantiles del París 68.

Los anteriores, fueron tiempos donde, en el arte local, cuajaron las vanguardias, con la introducción del Arte Conceptual. En los ochentas, tanto Otto Apuy como Rafael Ottón Solís, realizaron también una importante estadía en España, asimilando el Arte Matérico, el Arte Póvera, el Expresionismo Abstracto, el Arte Sígnico-gestual, y la Neofiguración. Por otro lado, Zulay Soto, quien se interesaba en el collage, colectaba noticias del acontecer social y político, los sensibles argumentos del Pop Americano; ella conoció también de la masacre estudiantil de Tlatelolco y, muy importante, los desfiles en San Francisco de los Hippies, que introdujeron el Happening y el Performance. En este contexto cultural creció Karla; ella asistió a la educación y se formó en Diseño de Publicidad en la Universidad Véritas; por lo tanto, es más que conocedora del impacto de los medios masivos de comunicación y su influencia en la representación de la cultura visual en la cual estamos insertos.

Karla era una niña para entonces, pero esas referencias históricas y culturales debieron llegar a sus oídos para despertar el deseo personal de trasgredir con el arte, donde el nudo central era el desnudo de su propio cuerpo y la posibilidad que se abría -luego de las experiencias pasadas con el happeningde encontrar audiencias para estas manifestaciones, lo mismo que el performance.

Resulta importante destacar - para conocer el contexto de esta artista- rememorar los tiempos en los que ella creció: la creación del Instituto Tecnológico en Cartago, la Universidad Nacional en Heredia y la Universidad Estatal a Distancia; asimismo, el clima político no era del todo tranquilo, por la persistencia de la Guerra Fría; también, los conflictos bananeros habían marcado la historia social del país, resonancias que embargaban las expresiones visuales y la memoria histórica del país. Resaltan también las luchas de los grupos de izquierda que se oponían a la llegada de las transnacionales al país, para explotar sus recursos naturales, como la de ALCOA, en los años setentas. En ese contexto se creó el Museo de Arte Costarricense, en el espacio que ocupaba el antiguo aeropuerto en La Sabana.

Aquellos tiempos escolares y colegiales también la formaron en sus actitudes y aptitudes artísticas, al presenciar todos estos cambios, como la aparición de las primeras computadoras en la década de 1990, las impresoras y el uso de la fotografía que, a finales de esa década, abrió nuevas expectativas, sumado a la cámara digital y al uso del video para la creación artística. Fueron tiempos del auge de la literatura regional, la música y el cine, prácticas que expandieron los efectos especiales, 


\section{Reflexiones}

la creatividad en los escenarios y el uso de recursos tecnológicos, que, de alguna manera, incidieron también en el abordaje a la obra de arte y los discursos de la contemporaneidad. A la pregunta sobre ¿qué aspectos de esa cultura cambiante le motivaron a crecer y asumir la realidad de esos años?, la artista comenta acerca de libros y películas que incidieron en su formación:

Yo diría que las películas de Mike Cahill Orígenes y La otra tierra, y los libros de Michael Brown El proceso de la presencia y La alquimia del corazón, me ayudaron a tener una relación más consciente con mi yo espiritual, y la consideración de la "Pachamama" que me cambió la forma de ver y sentir la actualidad.

\section{Grupo generacional}

Es posible que olvide a alguno, sin embargo, es importante citarlos, pues formaron un cambio generacional motivados por el arte conceptual, el uso creativo de la cámara fotográfica y la de video, el arte en los espacios e intervenciones públicas como el performance o las acciones, y los "grafiteros" quienes transforman la visual del paisaje urbano. Ellos fueron Lucía Madriz, Sila Chanto, Adrián Arguedas, Emilia Villegas, Héctor Burke, Carlos Bermúdez, José Pablo Solís, Adela Marín, Sussy Vargas, Mirta Castro, una generación impulsada en los inicios por el MADC. No obstante, también es importante nombrar la generación anterior, dentro de los cuales destacan Priscilla Monge, José Miguel Rojas, Manuel
Zumbado, Pedro Arrieta, Rodríguez del Paso. Y, finalmente, la generación posterior, conformada por José Alberto Hernández, Roberto Guerrero, Federico Herrero, apoyados por el MADC, los cuales representaron al país en bienales internacionales.

\section{Temas centrales}

Para el simposio Temas Centrales (2000), organizado por TEORéTICA arte+pensamiento, Karla trabajaba con el tema "Geografías" (2000) los espacios de su cuerpo, en donde indaga detalles como las fosas nasales, dientes, labios, vello púbico y comisuras de la piel, con los cuales recomponía el múltiple de su cuerpo. Esta, como participante en el foro de presentación de los artistas, expresa:

A través de mi trabajo pretendo hablar sobre lo físico y lo espiritual, la vida y la muerte, lo real y lo aparente. Casi siempre utilizo mi propia imagen, pues de hecho hablo de mis inquietudes personales. Sin embargo, no pretendo encontrar respuestas definitivas, sino más bien sugerir preguntas al espectador. (TEORéTica, 2000)

En estos años, la artista trabaja con la piel de sus manos o partes del cuerpo; cose, hila o escribe palabras que evocan la vida, los conflictos y sinsabores de las relaciones humanas, de pareja, o clama por equilibrio ante tanta tensión en el sistema social y cultural. Temas Centrales sirvió de laboratorio, donde se observaron esas conductas y sus repercusiones. En ese contexto, recuerdo el 
performance de la guatemalteca Regina José Galindo, quien se dejó abandonar en una de los torres vigías de los muros del Centro de la Cultura y la Ciencia, donde se encuentra, actualmente, la Galería Nacional, la antigua penitenciaría de San José; aquí, Galindo se dispuso desnuda, con moretes en su piel violentada por tanta circunstancia hostil, sobre todo, contra la mujer y que, a 16 años de realizado ese performance, las cosas todavía no cambian nada.

\section{El cuerpo comestible}

Para esos años 2000, era reciente el tema de la antropofagia, el cual se abordó, de manera inicial, por la Bienal de Sao Paulo. Karla lo considera en un par de eventos como idea para una acción que realizó en la Galería Nacional, cuando, en 2003, tuvo lugar la Primera Confrontación en el Arte, con cuarenta artistas y cuatro curadores. Aquí, Karla preparó un gran pastel y en cuyo lustre lucía impresa una fotografía de las zonas íntimas de sí misma; el performance -simbolizando la antropofagia - ante la expectación del momento, consistió en invitar a los espectadores a comer un trozo de aquella metáfora de su propio cuerpo.

\section{Remendar la piel}

Durante esta etapa de la vida de Karla Solano -la cual va de finales de los años noventa a inicios de los dos mil- esta intensifica sus motivaciones cruciales al reflexionar sobre su humanidad, los detalles de su anatomía y la exploración de la piel. De su video-fotografía Sewing/Hogar (2005), la desaparecida curadora Virginia Pérez-Ratton comentó: "Solano ha articulado su trabajo artístico en torno a la propia corporalidad como metáfora de diversos aspectos de la existencia y de la condición humana" (Pérez-Ratton, 2009).

\section{Mudar la piel}

De forma posterior, Solano exhibe en el año 2010, en la Sala 1 del Museo de Arte y Diseño Contemporáneo, una nueva propuesta en la cual vuelve a tematizar esa visión de sí misma en relación con los fenómenos que pueden afectarla como criatura sensible a las transmutaciones del tiempo. María José Chavarría, curadora de la muestra, menciona al respecto:

La artista nos presenta una mirada introspectiva del cuerpo como escudo, como lienzo, como catarsis. Pequeños trozos de un todo, detalles que se magnifican, momentos donde la fotografía es testigo del transcurrir de los años como partes de una historia inconclusa.

La corporalidad como eje central en la obra de Solano, nos permite hacer un acercamiento al estudio del retrato. La desnudez se presenta no como tema, sino como recurso para explorar el detalle, rescatar el gesto, el instante; para reflexionar sobre la existencia misma. (Chavarría, 2010) 


\section{Reflexiones}

\section{Fotografía y espacio arquitectónico}

Una de las características de los proyectos de Karla Solano expuestos a inicios de la segunda década de este siglo XXI, indica el interés por intervenir los espacios arquitectónicos con impresiones de fotografías de su cuerpo; así lo hizo con la fachada del Museo de Arte Costarricense en 2010, al adherir una película fotográfica al ventanal y puertas de acceso, afinando la metáfora del ingreso al museo, como una representación de penetración simbólica al interior de su humanidad. Este aspecto no es nuevo en el imaginario de esta artista; existe un precedente con la mencionada foto instalación "Yo soy tú" (1996) de la colección del MADC, cuando, entre las partes fragmentadas, dispuso un espejo, de manera que los espectadores, al colocarse delante de la pieza, se observaban inmersos en el interior de su pieza.

Activa con esta percepción, la interrogante sobre el significado de una experiencia de naturaleza metafórica entre el cuerpo y el espacio arquitectónico, continuó en la mente del artista. Quizás ese sea su principal talento, el cual enmarca en su reciente trabajo. Al preguntarle sobre estos aspectos, esta responde que su búsqueda está dirigida a convertir esos espacios utilitarios, que a la vez son rígidos - como los espacios arquitectónicos-, para reinventarlos en una forma orgánica -humana-, dentro de la cual el visitante pueda vivenciar dicha forma orgánica al hacer ingreso a sus adentros de artista.
No obstante, aún hay más. Este espacio que experimenta la metáfora del cuerpo es el suyo propio, e intenta cuestionar o entablar una reflexión sobre lo que plantea la fotografía de estos años, utilizando los recursos tecnológicos existentes en materia de impresión, los cuales posibilitan implicar lo construido, como la gráfica mural, la arquigrafía y la gigantografía. Karla descubre estos recursos, los reconoce y los aplica, explorando nuevas incidencias, no solo de la fotografía en el contexto urbano, si no de su cuerpo que se apropia de esa interacción con la ciudad. Añade que ese es su cuerpo, debido a que son sus propias inquietudes; sin embargo, al estar expuestas dichas inquietudes -interviniendo el entorno público-, pueden ser las de otros y, a partir de ese insumo, estas logran generar pensamiento e invitan al espectador a asumir una postura personal delante de su trabajo.

\section{La gran caverna}

En una de mis constantes reflexiones sobre el trabajo de esta artista -las cuales publiqué en 2013 en mi blog de Experimenta Magazine- comenté la visión de la gran caverna, cuando los individuos andan en busca de vivenciar el acto de volver al útero materno, del simbolismo de la caverna o el gran vientre terrestre. Dicha búsqueda implica asumir el vínculo protector, donde todo es dado y se abastece al ser humano con la energía del amor; ahí el individuo crece y es infundado de carácter, la genética; esta experiencia lo 
Figura 1

Espera (s.f.)

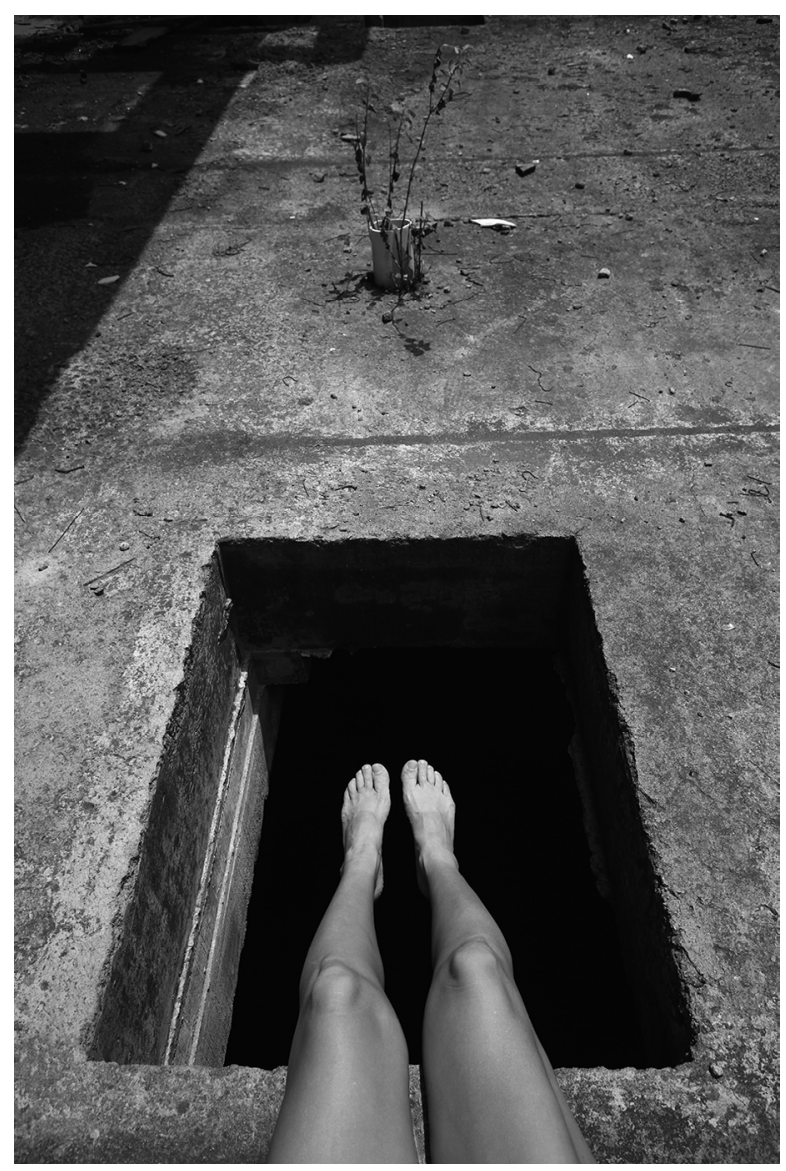

Fuente: Karla Solano

prepara para el existir futuro donde gozará independencia y logrará externar los rasgos de su propia personalidad.

En la referida publicación, pregunté a Karla si ese aspecto de la sicología - tan de naturaleza humana- en donde el individuo aprende a apropiarse del mundo en el cual nacerá, crecerá y morirá, se encuentra presente en su aguda propuesta fotográfica. Ante dicho cuestionamiento, su respuesta fue afirmativa, ya que, en varias de sus obras, ella se coloca en posición fetal -que es la forma más segura de estar en conexión con lo existencial y/o natural- y piensa que, a través de ese gesto tan primigenio, logra recordar esa sumersión en la que el ser humano carecía de hambre, frío o calor, entre otros, refugio ideal que libera de las vicisitudes y de la realidad; aquel que sustenta el sentido metafórico de sus intervenciones a lo construido, a la horma arquitectónica que también "hace" al ser humano. En este sentido, la autora reinterpreta este estado, para que el observador experimente la evocación del trance de nacer y cargue de su propia fuerza a la lectura que haga de su obra.

Insistiendo sobre este aspecto de la evocación vivencial del estar en el vientre materno, las contingencias del parto y la simbólica relación con el espacio arquitectónico, insistí en preguntarle sobre qué percepción brinda el espacio cerrado para entablar comunicación, desde la experiencia del espectador. En esa oportunidad, ella respondió que realiza proyectos en lugares cerrados como salas de museos, edificios institucionales, ya que estos provocan sensaciones muy fuertes en el espectador; no obstante, prefiere las intervenciones en sitios públicos y abiertos, para que su obra alcance mayor proyección.

Cuando aparece la oportunidad de reunirse con algún artista, me motiva dilucidar estos aspectos de la naturaleza de la obra de arte, en sus aspectos ontológicos y epistemológicos; por lo que quería insistir en 


\section{Reflexiones}

preguntarle ¿cómo nace cada fotografía o instalación suya?, ¿cuáles son sus activadores emocionales o aquellos matices motivacionales que le impulsan a hacer sentir al espectador lo mismo que ella siente?, o ¿qué le permite implicar emocionalmente sus propuestas para tocar la psicología del espectador?, ¿dónde encuentra esos activadores para elaborar el lenguaje que va a cargar a sus propuestas?

Ante las anteriores interrogantes, ella explica que todos los factores involucrados en sus propuestas nacen de vivencias personales, las cuales no busca; por el contrario, solo suceden. Ella habla de actitudes ante la feminidad, la vida, la muerte, el amor, el desamor; temas que son recurrentes en su trabajo y, por tanto, se reflejan en su intensa experiencia creativa y en su vida como persona.

\section{Lenguaje e introspección}

La estética del cuerpo, el goce pleno de la sensualidad humana, el uso de signos como la curva y contra-curva abierta, son componentes del lenguaje presentes en el trabajo de esta artista, portadores simbólicos que reflejan lo que ocurre en su interior. Entonces, ¿cómo edificar el concepto, activando esos elementos importantes en la comunicación humana y, en este caso, de la obra de arte? Para ella, utilizar su cuerpo como entidad comunicante de su obra, se da por la circunstancia de que le es cercano, es cambiante y frágil y no por su estética ni sensualidad; sin embargo, el espectador, en la libertad de
Figura 2

A través (s.f.)

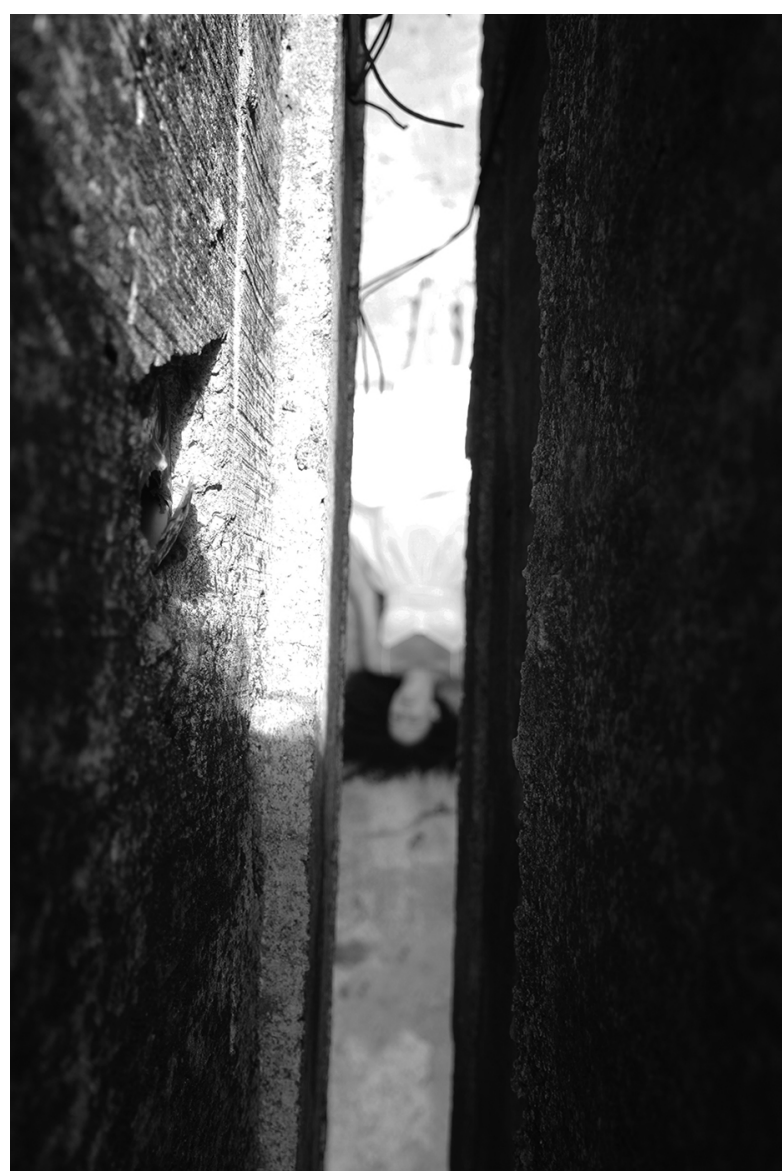

Fuente: Karla Solano

interpretar el arte que percibe en una muestra, al disponerse a reflexionar delante de la obra de arte, puede tener esas lecturas sobre su trabajo, si así lo desea.

Preciso este anterior aspecto, que no deja de ser incómodo de tratar, pues en mi caso personal, me interesa esculcar las reacciones del público ante una obra como la de Karla 
Solano y así, meditar cómo les afecta al estar de frente a una pieza como Espejo Interior, ante la desnudez de su cuerpo, donde podría aparecer en los observadores esas cargas de morbosidad, sobre todo en el público masculino. Las reacciones son muy diversas, tanto como personas existen, lo observé en exposiciones acá en el país, y en la itinerancia de la muestra MESóTica en Roma y Turín, en tanto me tocó organizar su montaje en estas ciudades italianas; ahí me topé con una verdad que intentaba alcanzar su certeza: la naturaleza humana en materia de sexualidad, se comporta de manera muy similar, sin importar las altitudes y latitudes, sociales y culturales donde se encuentren; sin embargo, este puede ser tema para futuras investigaciones multi disciplinarias.

\section{Figura 3}

Espacio (s.f.)

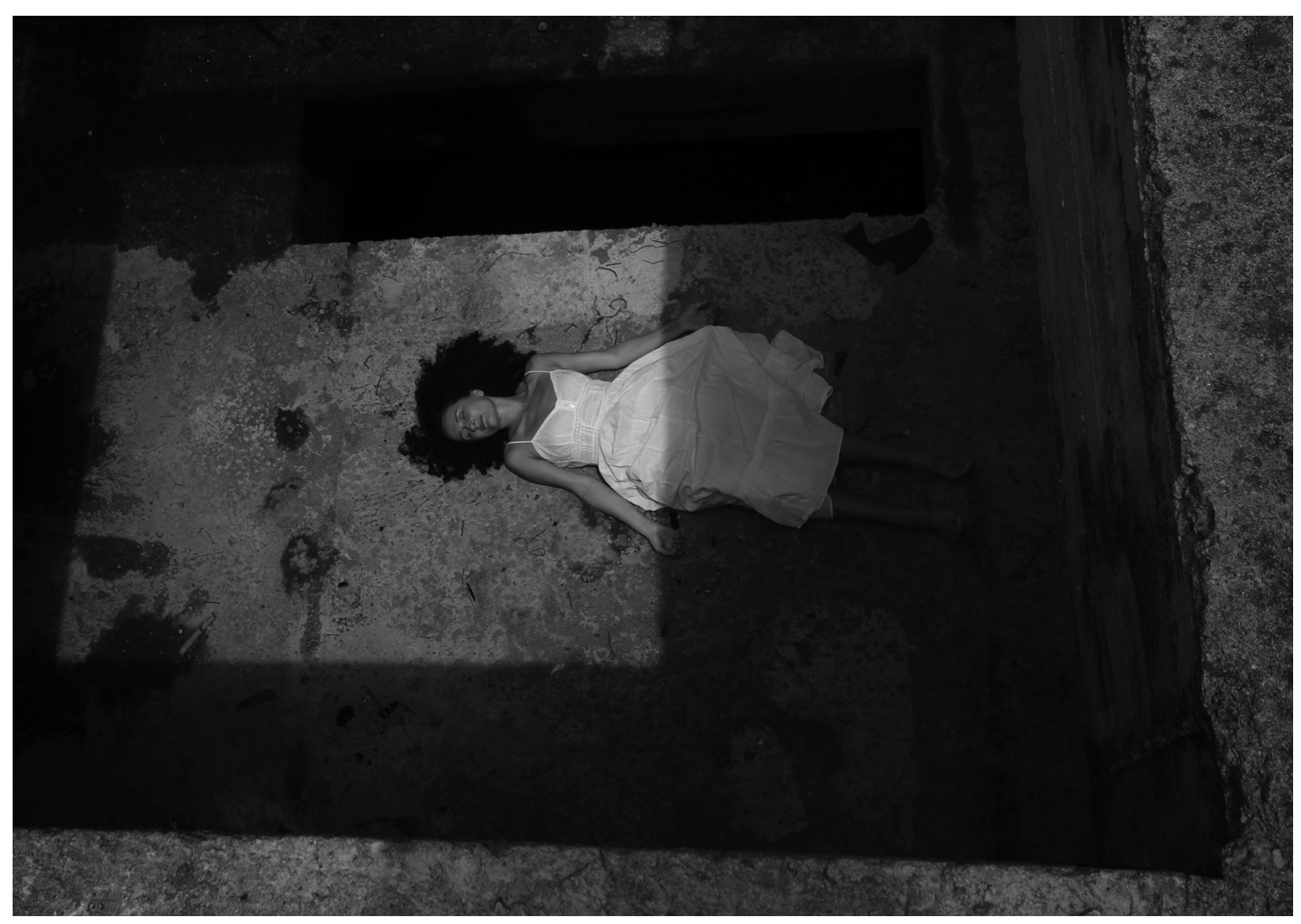

Fuente: Karla Solano 


\section{Reflexiones}

Volviendo a la relación entre espacio interior o exterior y su obra, cuando converso con ella y/o evoco sus propuestas, me intriga conocer su criterio de cuándo actúa la artista, quien pretende provocarnos a través de la expresión, y quien pone en el tapete el disenso sobre las relaciones humanas, sociales, culturales, y otras conexiones tan presentes en los discursos de actualidad en el arte contemporáneo. Entonces, me pregunto, ¿cómo conjuga esas posturas para regenerar el interés en la fotografía? ¿Cómo intrinca con el espectador para que este siga el hilo de su pensamiento crítico, signos vertidos en el espacio público o privado, externo o interno?

En relación con lo anterior, comenta Karla, todo inicia con una introspección, con un trabajo muy íntimo, personal; una vez expresado este encaje que fortalece la idea del proyecto, se encuentran las relaciones con esa sociedad, y se descubren conexiones conscientes $\mathrm{o}$ inconscientes que hablan de una realidad y cuestionan conductas respecto a la existencia humana.

\section{Del lado del corazón}

Con la obra Cuerpo Geométrico que expuso en 2015 en la comunidad de Teruel, Aragón, España dispuesta en un espacio abierto $-y$ una vez realizado el boceto- ella descubrió que el espectador penetraba en el simbolismo de su cuerpo por el pecho, del lado del corazón. Lo anterior, convirtió a aquel cubo gigante (de cuatro por seis metros) en un cuerpo vulnerable, transparente y frágil, haciéndolo una metáfora de un cuerpo: todo aquel que lo deseara podía ingresar a formar parte de él. La intención de la artista radicó en estimular la conexión emotiva -quizás su componente materna o filial- y encadenar el lado afectivo del espectador, quien se hizo parte de la obra para cargarse de una vitalidad, hoy, amedrentada por el diario existir en una urbe tan instigadora y discordante como en la que se habita.

Así es la fotografía contemporánea; ya no solo informa o documenta la realidad sino que clava, deja la duda y suma al espectador en el epicentro del cuestionamiento donde este aporta su interpretación y, por lo general, emerge afectado por lo ignoto de tal paradoja. Karla Solano fue distinguida en el 2010 con el Premio Nacional Aquileo Echeverría, galardón que premia la mejor exposición del año, sus investigaciones y experimentación con nuevos materiales; en este caso, por la muestra realizada en la gran sala del Museo de Arte y Diseño Contemporáneo.

\section{Rituales}

En mi caso personal de observador acerca de la obra de arte actual, siento la responsabilidad de escribir -y no dejo de publicarlo en mis blogs de comentarios- en especial aquello que repercute y rescato de dichas percepciones. Si la muestra no deja nada o no me ancla para que fluyan mis reflexiones, me abstengo de hacerlo. Sobre el trabajo de Karla Solano, siempre encuentro frecuentes motivos para postear mis repercusiones de lo observado, siempre tengo preguntas para ella y, de esa manera, espero sus respuestas; es un ir y venir para despejar el enigma. 
Ejemplo de lo anterior es la muestra de Karla Solano en Klaus Steinmetz Contemporary (2015), la cual argumenta uno de sus principales ejes temáticos: el renacer. Esta refiere, además, a una de sus recientes producciones en video llamada Ritual (2015), en el cual abordó su manera de comprender el performance, acrecentado con sus fotografías el abordaje a la muerte corporal y el renacer del espíritu. Dramático video - comentaba en un post de uno de mis blogs- en el cual, el cuerpo desnudo de la artista despojada de todo orgullo humano, vacía de gestos y apariencias, donde yace en el frío ambiente de la morgue, sobre la camilla de concreto gris mortuorio. No obstante, de pronto, de las zonas laterales de la escena emergen dos jóvenes -sus hijas-, quienes la visten, la peinan, la maquillan y la preparan para entrar en aquella instancia oscura y tremenda de la última morada.

En la apertura de la muestra en Klaus Steinmetz Contemporary Karla realizó esta acción en la cual, entre telas blancas colgantes y la apropiación conceptual de la pintura "Ofelia” (1852), del inglés John Everett Millais

\section{Figura 4}

Ofelia (s.f.)

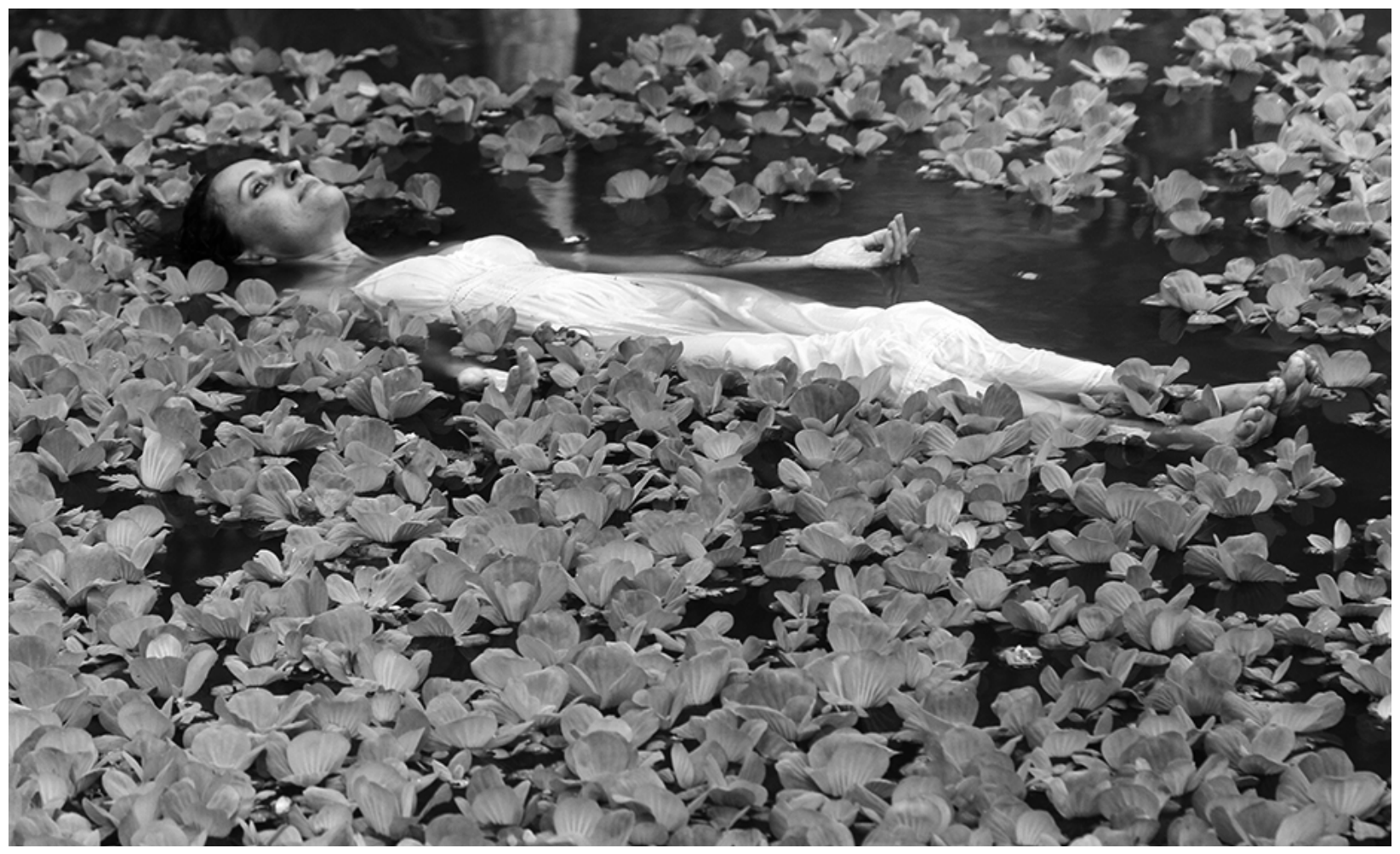

Fuente: Karla Solano 


\section{Reflexiones}

(1829-1896), trama el resurgir a la luz, al calor de la vida nutrida por una profusa e intensa naturaleza. Subrayo que en esta propuesta de 2015, Karla confronta los opuestos morir-renacer, al ingresar al recinto mortuorio donde reposa su cuerpo para de ahí saltar al renacer sumida en un estanque de aguas cristalinas; esta acción se concibe como sumirse de nuevo en el útero materno, en aquel líquido amniótico donde, a partir de la cuarta semana de gestación, flotamos adquiriendo los caracteres que aporta la genética y el espíritu de la vida, preparando el nuevo cuerpo para el instante de la gracia del nacimiento donde se asume la autonomía del ser.

Cuando intento indagar para tener una respuesta al desafío de la interpretación, la propuesta me intimida a rastrear datos visuales y contenidos que me conecten a la situación presentada, reconocer el terreno, el campo de actuación y, de esa manera, fundamentar al sujeto de estudio. De inmediato advierto claras recurrencias de simbolismos latentes como volver al útero, o la gran caverna del mundo, donde seremos renovados y de donde emergemos ataviados de pureza e inmaculado blancor. Ella lo experimentó, como se dijo, en la pieza que mostró en Teruel, España, Cuerpo Geométrico, donde edificó el espacio de aquel cubo, el cual estuvo recubierto por una enorme fotografía de su cuerpo, y a cuyo interior se podía ingresar a través de una abertura en la zona del vientre. Para esta nueva propuesta, el sentido de esos simbolismos suman al agua, al estanque de los nenúfares, y otras texturas ataviadas de referencias orgánicas propias del entorno de un jardín; ella renace en una naturaleza profusa de intensos verdores -como la pintura de Millais-, donde el sujeto es parte de un gran sistema que todo lo gobierna pero, a la vez, va en busca de la autonomía de ser y estar. Lo anterior, en tanto desafío, implica lucha, aprendizaje, manifestación, independencia y toma de conciencia.

\section{¿Por qué Ritual?}

En el caso de Karla Solano, cuando tengo que referirme a sus creaciones, siempre intento -como expliqué en la introducciónpreguntarle acerca de las ideas centrales para reafirmar mis supuestos. Por ejemplo, en Ritual, le pregunté del porqué del título, a lo que comentó que surge de la necesidad de contar una historia vivida. La autora, de esta manera, se refiere a instantes cruciales de su existencia donde probó vivencias cercanas a muerte que la marcaron profundamente. Estas respuestas a mis interrogantes acerca de su trabajo, las mantengo en apuntes y comentarios publicados, como ya mencioné, en mis blogs, los cuales resultan interesantes para que los lectores las conozcan:

Cuando tenía seis años -recuerda Karla-, llamaron a la puerta para avisar que mi mejor amiga había muerto... esa fue mi primer pérdida. Dos años después murió mi mascota, para la cual hice un entierro en el jardín de la casa y ocho días más tarde, por curiosidad, la desenterré para tratar de descubrir qué sucedía después de la muerte. Durante este evento realicé mis primeras fotografías y así comprendí que las cosas no acaban para siempre, se transforman. 


\section{Reflexiones}

Figuras 5, 6 y7

Ritual (2015)
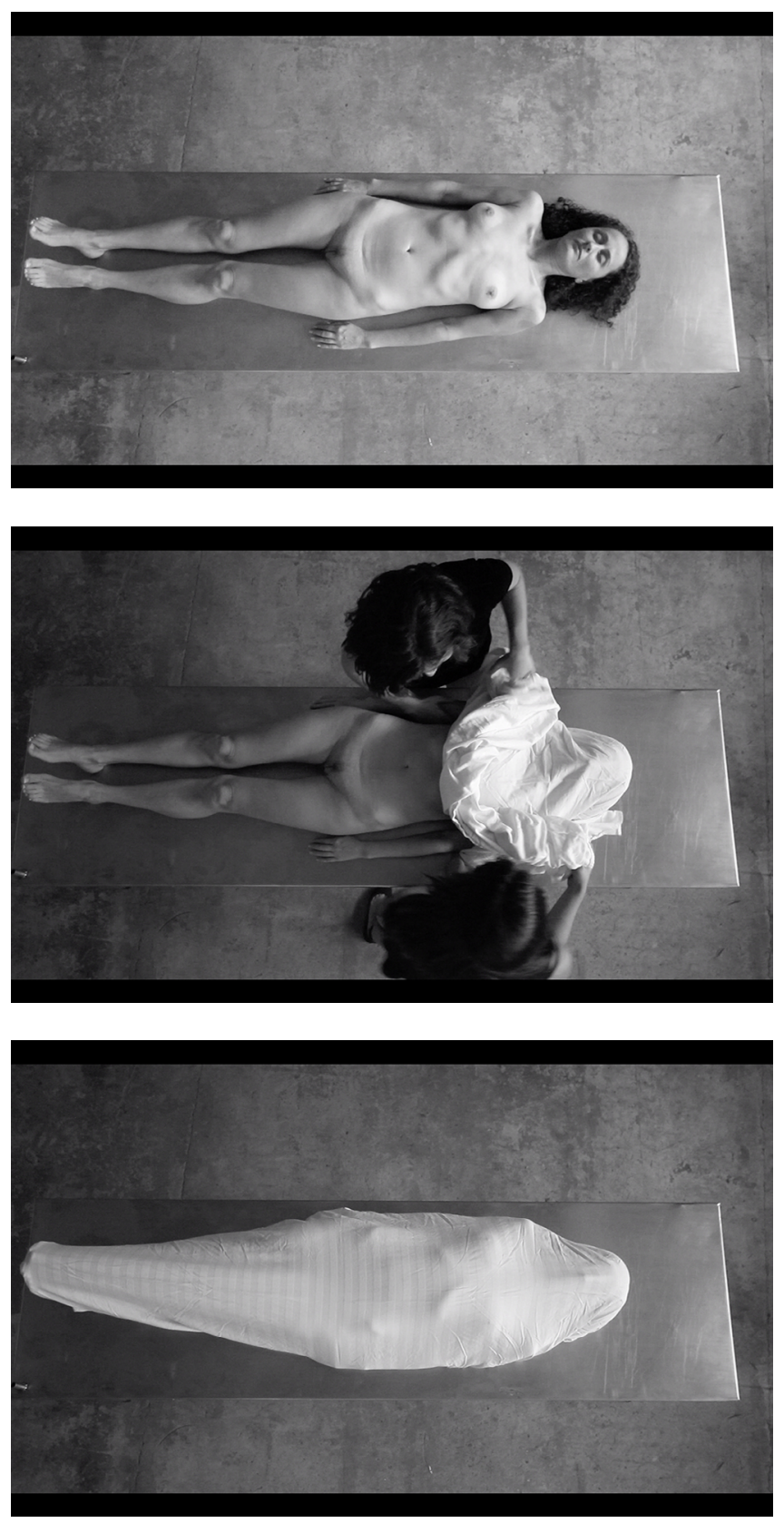

Fuente: Karla Solano

307 ESCENA. Revista de las artes, 2016, Volumen 75, Número 2, págs. 285-314 ISSN 1409-2522 
Al conversar con una persona creativa, como es el caso, indago qué es lo que se propone conseguir al afectar al espectador -razón vital de una exposición-, pues el artista no la realiza para sí mismo ni para que el público no obtenga ninguna experiencia al entrar en contacto con la obra. En una muestra se abre un intersticio de reflexión, un espacio donde el público advierta las claves de sentido de la propuesta, al transmitirle un sentimiento, cualquiera que sea. Pregunté entonces, ¿te interesa ese carácter motivacional capaz de incentivar la memoria para que el espectador recuerde, para que tenga memoria de su cuerpo, naturaleza, cultura humana, hasta nuestra comprensión de la vida y la muerte, para, como tú dices: transformarse? Definitivamente -responde Karla- "el cuerpo, la memoria, lo físico y lo real son temas recurrentes en mi trabajo". Ella se deja engullir por sus remembranzas, y con cierto extrañamiento agrega algo que la conmueve: "Cuando tenía trece años falleció mi padre, sin duda ese fue el detonante para que años después la muerte fuera el tema central en mi obra artística".

¿Qué apuntan esas recurrencias tan de naturaleza existencial? Lo físico y lo espiritual, lo real y lo aparente, los cambios internos y externos y el paso del tiempo se convirtieron en la vida de Karla en su mayor cuestionamiento y metáfora de la vida en imágenes:

Hace un par de años -vuelve a comentar-, experimenté el ritual de la muerte vistiendo y maquillando a mi abuela fallecida, experiencia que compartí con mi madre y mi tía. Su cuerpo en la morgue frío, desnudo, con grandes costuras, su piel sin color y su cabello despeinado. Toda la vanidad que pudo tener se terminó ese día en un segundo.

Aprovechando ese espacio tiempo tan críptico, le pregunté: ¿Con qué sentimientos describirías lo percibido para provocar al lector lo advertido en un momento tan fuerte y circunstancial? "Experimenté", fue su respuesta, y agrega, "[...] allí el amor más puro, la feminidad, lo sublime y espiritual son momentos que vuelven y hacen reflexionar, lo que significaba presentar a mi abuela ante la sociedad. A pesar de todo ella tenía que verse linda y con dignidad aún en el último momento de su vida".

Ya que tanto se habla de la muerte, cuando se dice que desde el instante mismo de nacer, comienza el camino hacia la morada final, ¿cuál es el sentido del simbolismo de volver a nacer tan presente en tus propuestas? Al anterior cuestionamiento, ella responde que existen muchas personas que están vivas pero no se dan cuenta de esta verdad; no valoran el hecho de respirar cada día. Comenta que en la actualidad sólo nos preocupamos por la apariencia física, el estatus económico e intelectual y la lucha constante por no envejecer: "Después de cuarenta y cuatro años de transitar la vida -agrega dando un gesto no verbal a su manos-, estas cosas son cada vez menos importantes para mí; continúo intentando recuperar la pureza que tenía cuando era niña". 


\section{Reflexiones}

Asimismo, instiga mucho saber el significado de estos simbolismos que de pronto aparecen en su obra. De tal modo ¿por qué el agua, el estanque, los nenúfares? El gesto de sus manos pasa a una mirada de certeza: "Porque estoy hablando de la vida, no de muerte, y estos elementos nos purifican y recuerdan la vida".

¿Será reinventarse a partir del acto de experimentar tan profundas oscuridades presentes en la actualidad? Es decir, al no encontrarse el individuo aislado del mundo y lo que repercute, afecta a todos. El sujeto se encuentra delante de un mundo cargado de la enorme crisis contemporánea: la violencia en la sociedad, la corrupción en las esferas políticas y del Estado; por tanto, es urgente la necesidad de renacer a nuevos valores para enfrentar de mejor manera el futuro. Ella comenta respecto a esta duda: "Todo esto, lo bueno y lo malo es la vida, lo importante es la forma en que asumimos estas condiciones; para mí, lo ideal, sería renacer cada día con una nueva piel".

¿De dónde proviene esa idea de sumirse en la cripta para reordenar nuevas formas de vida, ayudados por ángeles o hadas (sus hijas en el caso del video Ritual que, por cierto, también se exhibió en la muestra Muerte -la Ineludible-, 2016, en los Museos del Banco Central de Costa Rica, curada por María José Monge), las cuales son como ángeles quienes ostentan el poder de paliar los males del pasado y reorientar al emprender la ruta de retorno? A lo cual responde Karla: "Retornar al romanticismo y la tragedia en este momento de mi vida y de mi obra es mi mayor interés, mi intensión únicamente es aprender de lo vivido y compartirlo".

La presencia de Karla Solano en los ámbitos de la cultura costarricense así como las maneras que utiliza para decir, de expresar y marcar sus puntos de inflexión, ¿en qué ayuda el arte a catapultar dichos conceptos? Ella responde: "Por medio del arte, he experimentado una serie de rituales que han transmutado mi vibración, como un fénix reviviendo de las cenizas e intentando ser consciente de que la respuesta está dentro de cada uno.

\section{Las hojas caídas del árbol}

En la citada muestra "Muerte -la Ineludible-" curada por María José Monge y Priscilla Molina para los Museos del Banco Central de Costa Rica, Karla Solano presentó para la inauguración un performance en la zona central de las salas, en un espacio circular rodeado por las gradas de acceso a las salas, las cuales conforman una especie de foso, con tres niveles de altura; en el fondo de dicho espacio ella dispuso un redondel de hojas de árbol, donde anidar su cuerpo desnudo, asumiendo la posición fetal acostumbrada en sus acciones artísticas, determinada a renacer en ese entorno mágico, donde el público asistente ponía la mirada asombrada por el drama del momento, y desde el nivel superior caían cientos de hojas generando una sensación como de ventisca otoñal. El performance estuvo acompañado de la sonoridad de un contrabajo, que con sus graves acordes afectaba el enigmático 


\section{Reflexiones}

Figuras 8, 9 y 10

Fotosintesis (2016)
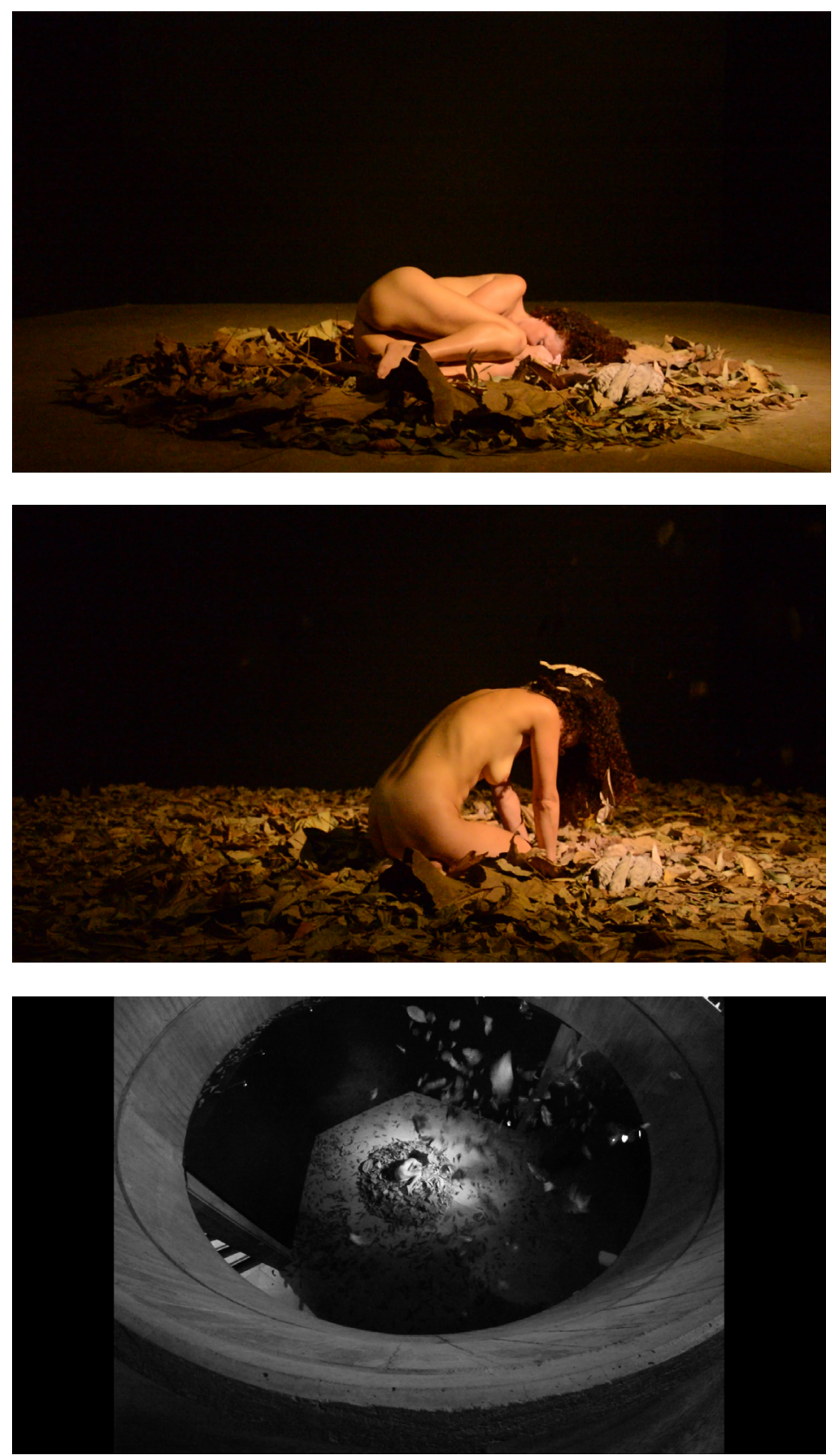

Fuente: Museos del Banco Central de Costa Rica 


\section{Reflexiones}

momento en el cual su cuerpo inmerso en la hojarasca volvía a la vida, bajo las miradas expectantes del público.

Ante estas expresiones tan intensas del arte actual, yo me pregunto ¿cómo afecta al espectador la génesis del arte en la idea de la artista de conjugar en el espacio museal esos simbolismos tan cargados de significados de la vida y la muerte? ¿Cómo explica ella esa simbiosis que enuncia la tierra, el árbol, la luz, la fotosíntesis, el vacío e idea de foso o cripta funeraria?

Karla, lo explica con muy pocas palabras: "La experiencia fue una experiencia increíble, mágica, como si todas las personas presentes de ponto desaparecieran en un instante que se hizo eterno, sin embargo, eran parte de aquel árbol gigante cuya corporalidad se elevaba dentro de la arquitectura del museo"

Me parece en suma significativo la introducción de este nuevo simbolismo en el imaginario de Karla Solano: el árbol, en tanto es signo de esperanza, como la gran ceiba tropical es el "Axis Mundi" para nuestra culturas antiguas, por la cual bajan al inframundo los espíritus y yacen buscando regenerarse para subir por sus raíces, tronco, y ramajes al supramundo, con la lógica conexión con la cartografía celeste, aumentando el drama del deambular buscando una luz que en este caso - y como expresé en mi comentario de esa muestra- la ponemos los vivos por medio del arte. El arte, en esa instancia terrible pero divina, juega el rol de las ofrendas funerarias; en el caso de nuestros ancestros indígenas prehispánicos -que a corta distancia de ese foso donde se realizó el performance se hayan expuestas como parte de la exposición una enorme cantidad de jarrones trípodes, metates, objetos de oro y otros componentes de orden simbólico-religioso-, y que se suma a esa sinergia del renacer para subir al árbol de la vida; gracias a las insistentes intercesiones de los vivos por medio de las jaculatorias que rezan a Nuestra Señora del Carmen, madre de las almas en purga, cuyo ícono también está presente en la muestra.

Obsérvese que además se mezclan diversos niveles o capas culturales, sociales e históricas: el de nuestros pueblos originarios. En la primera mirada a las fotografías de este performance de Karla las cuales observé en redes sociales, ligué a esta cultura del antepasado, en tanto se presencia la idea de la espiral, de excavación o morada final donde un cuerpo subyace bajo la hojarasca en espera de la luz, la cual la ponen los vivos por medio de sus intercesiones, rituales propiciatorios $\mathrm{u}$ ofrendas, para llevarla a renacer hacia esa otra vida, donde finalmente se encuentra la paz, la total luminosidad, ante tanta contingencia, y que ella trató en su anterior performance Ritual, expuesto el año pasado en Klaus Steinmetz Contemporary. $\mathrm{Al}$ respecto Karla expresa que ella no pensó en ningún nombre específico para esta trama performativa; sin embargo, menciona que en ningún momento la abandonó la idea de la fotosíntesis, por tratarse del árbol y esa luz renovadora y regeneradora de la segunda vida después de la muerte corporal que se manifiesta en los torrentes de la clorofila que recorre hasta el mínimo ramaje del árbol. 


\section{Reflexiones}

\section{A manera de conclusión}

En el comentado evento anterior Ritual, Karla Solano se sustentó en la idea del resurgir a la luz desde las aguas de la vida aquellos líquidos amnióticos donde ayer nadamos en el vientre materno durante los meses previos al parto-, en esa oportunidad sumida en un estanque y rodeada por una profusa e intensa naturaleza.

Arribado a la reflexión final y conclusiones, pienso que al madurar esta aproximación a su trabajo, temática y recurrencias técnicas y estilísticas, vislumbro un punto de inflexión que tiene que ver con abordar nuevos espacios de expresión y construcción de sus futuras propuestas: cambia la persistencia del espacio arquitectónico por la presencia del verdor y la naturaleza, lo cual demuestra con su participación en la recién inaugurada "Muerte -la Ineludible-, en los Museos del Banco Central, de febrero de 2016.

Es lógico y natural que después de la sumersión en las aguas purificadoras de la acción artística, ella intente conducirse hacia otro nivel de esa búsqueda emprendida en retrospectiva: buscar su cuerpo, saber de sí. Lógica evolución, ¿tendrá que ver con la tierra y el planeta que habita?, ¿volverá a las aguas purificadoras del renacer?, ¿intentará de nuevo invitar al espectador a ingresar al núcleo vivencial de su interioridad? Sólo Karla Solano lo sabe, dejemos pues que ella vuelva a sorprendernos y tengamos de nuevo que aguzar la mirada y encender el motor que anima nuestro pensamiento, su ánima, puesta en su intenso trabajo.

\section{Referencias}

Cazali, R. (1998). El Cuerpo en/de la fotografía. San José: Museo de Arte y Diseño Contemporáneo, p.28. (Sin ficha catalográfica).

Chavarría, M.J. (2010) Mudar la piel. San José: Museo de Arte y Diseño Contemporáneo, p.28. Catálogo de la muestra.

Pérez, V. (2009) Diálogos y Correspondencias. San José: Museo de Arte y Diseño Contemporáneo, p.8. (Sin ficha catalográfica).

Pérez, D. (1996). Espíritu de una Colección. San José: Museo de Arte y Diseñó Contemporáneo, p.59.

Pérez, V. (2009). MADC Un museo vivo. San José: Museo de Arte y Diseño Contemporáneo, p.61. (Sin ficha catalográfica).

Pérez, D. (1997). MESóTica II /Centroamérica Re-generación. San José: Museo de Arte y Diseño Contemporáneo.

Quirós, L.F. (2016). Árbol de Miradas. Recuperado de http://arboldemiradascr. blogspot.com/2015/05/karla-solano-rituales.html

Quirós, L.F. (2016). Karla Solano: Fotografía y espacio arquitectónico. Recuperado de http://www.experimenta.es/blog/ luis-fernando-quiros/karla-solano-fotografia-y-espacio-arquitectonico-4026

Quirós, L.F. (2016). Instancia innombrable. Recuperado de https://luisfernandoquiros.wordpress.com/2016/02/26/ instancia-innombrable/ 


\section{Reflexiones}

Solano, K. (1998). El Cuerpo en/de la fotografía. San José: Museo de Arte y Diseño Contemporáneo, p.28. (Sin ficha catalográfica).
Solano, K. (2000). Temas Centrales. San José: TEORéTICA, p.200. (libro del evento sin ficha catalográfica). Statement. 